Article

\title{
Screening of Deletion Variants within the Goat PRDM6 Gene and Its Effects on Growth Traits
}

\author{
Zhen Wang ${ }^{1,2,3,+}$, Congliang Wang ${ }^{1,2,+}$, Yongni Guo ${ }^{1,2}$, Shuaishuai She ${ }^{1,2}$, Baojing Wang ${ }^{1,2}$, \\ Yuru Jiang ${ }^{1,2}$, Yangyang Bai ${ }^{1,2,3}$, Xiaoyue Song ${ }^{1,2}$, Longping $\mathrm{Li}^{1,2}$, Lei Shi ${ }^{1,2}$, Lei Qu ${ }^{1,2}$, \\ Xianyong Lan $^{3, *}$ and Haijing $\mathrm{Zhu}{ }^{1,2, *}$ \\ 1 Shaanxi Provincial Engineering and Technology Research Center of Cashmere Goats, Yulin University, \\ Yulin 719000, Shaanxi, China; wangzhenid@126.com (Z.W.); wcl15596064203@126.com (C.W.); \\ guoyongni@126.com (Y.G.); sheshuaishuai0513@126.com (S.S.); wangbaoj@126.com (B.W.); \\ jiangyuru@126.com (Y.J.); bai345@126.com (Y.B.); songxiaoyue@yulinu.edu.cn (X.S.); \\ 1lp_315@163.com (L.L.); shilei_ylxy@126.com (L.S.); ylqulei@126.com (L.Q.) \\ 2 Life Science Research Center, Yulin University, Yulin 719000, Shaanxi, China \\ 3 Key Laboratory of Animal Genetics, Breeding and Reproduction of Shaanxi Province, College of Animal \\ Science and Technology, Northwest A\&F University, Yangling 712100, Shaanxi, China \\ * Correspondences: lanxianyong79@nwsuaf.edu.cn (X.L.); haijingzhu@yulinu.edu.cn (H.Z.) \\ + These authors equally contributed to this work.
}

Received: 14 January 2020; Accepted: 23 January 2020; Published: 27 January 2020

check for

Simple Summary: Genome-wide association studies found that the PR/SET Domain 6 (PRDM6) gene mutation was associated with bone development, bone density, and body mass index. This study found a 12 bp deletion variation within the PRDM6 gene in Shaanbei white cashmere goats in a large sample size $(n=1044)$. This variation polymorphism was associated with multiple goat growth traits in the yearling period, including heart girth $(p=0.027)$, cannon circumference $(p=0.008)$, chest depth $\left(p=2.10 \times 10^{-5}\right)$, chest width $(p=0.004)$, body height $(p=0.032)$, body length $(p=0.044)$, and hip-width $(p=0.014)$. The effects of the $12 \mathrm{bp}$ variation were found to make no difference on adult goat growth traits. Taken together, these results demonstrate that the $12 \mathrm{bp}$ deletion variant plays an important role in the early growth and development of goats and could be considered as a useful and effective molecular marker for goat breeding selection in the growth stage.

Abstract: By genome-wide association studies, the PRDM6 gene has been shown to affect multiple, apparently unrelated inherited traits, including bone density and body mass index. Therefore, it is considered a potentially pleiotropic gene. In this study, we identified a $12 \mathrm{bp}$ deletion variant (NC_030814.1:rs651603667, g: 79985625-79985636delTTGACTGATCCA) within the PRDM6 gene in a large sample (SBWC goats; $n=1044$ ). All goat samples were collected in Shaanxi province in July 2018. The frequency of the wt allele was higher than the frequency of the del allele, and this mutation polymorphism confirmed to be consistent with the Hardy-Weinberg equilibrium $(p>0.05)$. Further results showed that in a group of goats in the yearling period (18 months old, $n=567)$, this deletion variant of the PRDM6 gene was associated with heart girth $(p=0.027)$, cannon circumference $(p=0.008)$, chest depth $\left(p=2.10 \times 10^{-5}\right)$, chest width $(p=0.004)$, body height $(p=0.032)$, body length $(p=0.044)$ and hip-width $(p=0.014)$. For adult SBWC goats (36 months old, $n=477)$, the effects of the $12 \mathrm{bp}$ variation on growth-related traits were found to make no difference. These findings show that the 12 bp deletion within the goat PRDM6 gene plays an important role in the early growth and development of goats. Using the $12 \mathrm{bp}$ mutation, breeders can quickly and effectively select excellent individual goats at an early stage.

Keywords: goats; PRDM6; deletion; growth traits; correlation analysis 


\section{Introduction}

China is rich in livestock resources and has a wide variety of animal species, which means that the development and utilization of multiple livestock species deserve our attention. Livestock serves the human population in many ways, in particular, by providing protein-rich meat. Goat meat, with its rich nutrition favored by meat consumers, plays a vital role in daily diets [1,2]. For instance, goat meat contains low levels of cholesterol and intramuscular fat [3]. However, in many countries, and in China, in particular, poor production performance and quality still represent a bottleneck that restricts the advancement of goat meat production [4]. Hence, finding useful and practical measures to improve goat growth traits is urgent. As a meat-fleece hybrid goat breed, Shaanbei white cashmere (SBWC) goats have excellent fluff producing properties. However, they still have the disadvantages of small body size, slow growth and a long raise period; therefore, it is meaningful to pay attention to the breeding of growth traits in SBWC goats. By traditional methods, the breeding process in the goat industry generally requires a lot of time, which is inefficient and costly. With the development of modern breeding technology and breeding industry, we wanted to explore a useful and efficient way to promote goat growth traits and enhance economic performance. Many studies have confirmed that polymorphisms of some candidate genes could be associated with economic traits in livestock [5-7]. Van Laere found that a G to A nucleotide mutation appeared in intron 3 of porcine IGF2, which abolishes BED-type containing 6 repressor (a kind of transcription factor) binding and affected pig meat production [8]. Therefore, the genetic selection of economic traits in goats has been widely studied and reported and is of particular significance [9-11].

Recently, using genome-wide association studies (GWASs), the PRDM6 gene has been shown to affect multiple, apparently unrelated inherited traits, including bone density and body mass index; therefore, it was regarded as a potentially pleiotropic gene [12,13]. The formation of the skeleton is part of the early development of an organism [14,15]. Hu et al. found that the PRDM6 mutation was associated with bone development, bone density, and body mass index [12]. We hypothesized that the PRDM6 gene might play an essential role in early growth stages and might affect goat growth and development. However, whether the PRDM6 gene mutation will influence the growth traits and body shape of goats has still not been reported and is not yet clear. In this study, we investigated whether PRDM6 is related to goat growth in the yearling (18 months old) and adult (36 months old) periods, to provide some scientific basis for the efficient and rapid development of the goat industry.

\section{Materials and Methods}

\subsection{Ethics Statement}

The Faculty Animal Policy and Welfare Committee of Northwest A \& F University under contract (NWAFU-314020038) approved this experiment, and the experimental process complied with protocols of international guide for the ethical use of animals in research.

\subsection{Goat Ear Tissues and Collection of Growth Trait Data}

A total of 1044 healthy female SBWC goats, including 567 yearlings (18 months old) and 477 adults (36 months old), were selected randomly to make sure the individuals were not related. Yearling means that goats have not reached body maturity and have not been mated, and adult means that these goats have reached body maturity and have been mated. They were raised on a Shaanbei white cashmere goat farm in Shaanxi Province. Their feeding and living conditions were the same. Growth trait data of SBWCs were measured according to our previous methods [16,17], including heart girth (HG), hip-width (HW), cannon circumference (CC), height at hip cross (HHC), chest depth (CD), chest width $(\mathrm{CW})$, body height $(\mathrm{BH})$, body length (BL) and body weight (BWT). All growth trait data were verified by the technical agricultural station [11]. All ear tissues were collected in July 2018 and immediately soaked in $75 \%$ alcohol and taken back to the lab and frozen at $-80{ }^{\circ} \mathrm{C}$. Genomic DNA was isolated using the high salt-extraction method from ear tissues [18]. The concentrations of 1044 samples were 
measured by a Nanodrop 2000 Spectrophotometer, and were diluted to $20 \mathrm{ng} / \mu \mathrm{L}$ and frozen at $-40{ }^{\circ} \mathrm{C}$ for further experiments $[19,20]$.

\subsection{Primer Design and PCR Amplification}

From the Ensembl database (https://asia.ensembl.org/index.html), we found goat PRDM6 gene variations. According to the variant table of the PRDM6 gene, two putative deletion mutations in upstream and intron 1 of the PRDM6 gene had not been identified before. The two pairs of primers were designed by Primer-Blast of the NCBI website (https://www.ncbi.nlm.nih.gov/tools/primer-blast) based on the goat PRDM6 sequence (NC_030814.1). The PCR reaction contained 1.2 ng genomic DNA using the touchdown PCR procedure. PCR amplification was performed with an initial denaturation at $95^{\circ} \mathrm{C}$ for $5 \mathrm{~min}$, followed by 18 cycles at $94{ }^{\circ} \mathrm{C}$ for $30 \mathrm{~s}, 68^{\circ} \mathrm{C}$ to $50{ }^{\circ} \mathrm{C}$ for $30 \mathrm{~s}$ and $72{ }^{\circ} \mathrm{C}$ for $12 \mathrm{~s}$, then 34 cycles at $94{ }^{\circ} \mathrm{C}$ for $30 \mathrm{~s}, 50{ }^{\circ} \mathrm{C}$ for $30 \mathrm{~s}$ and $72{ }^{\circ} \mathrm{C}$ for $12 \mathrm{~s}$, with a final extension at $72{ }^{\circ} \mathrm{C}$ for $10 \mathrm{~min}$. PCR products were detected by Sanger sequencing and electrophoresis in agarose gel at $3.5 \%$ concentration [21].

\subsection{Statistical Analyses}

Associations of the $12 \mathrm{bp}$ variation locus within the PRDM6 gene with the growth traits of all 1044 individuals were determined using a linear model to show the effects of different parameters on the growth traits of goats. There were influences of different parameters on growth traits: $S_{i j}=\mu+G_{i}+Y_{j}+e_{i j}$. $S_{i j}$ represents the values of growth traits, $\mu$ is the mean, $G_{i}$ is the genotype effect, $Y_{j}$ represents effects of age, and $e_{i j}$ is random error [22]. One-way analysis of variance was performed to analyze the correlations between genotypes and growth traits using the SPSS 23.0 software [11]. The analysis results are presented in the form of mean \pm standard error (SE). Homozygosity (Ho), heterozygosity (He), and the polymorphism information content (PIC) were calculated according to a previous method [23]. Ho, He, PIC, and the Hardy-Weinberg equilibrium (HWE) were performed using the SHEsis website (http://analysis.bio-x.cn) [24,25].

\section{Results}

\subsection{Identification of Insertion/Deletion Polymorphisms within the PRDM6 Gene}

From the Ensembl database (https://asia.ensembl.org/index.html), two putative deletion variants were detected in goat PRDM6 (rs656578433; rs651603667), and their specific positions are shown in Figure 1. The 9 bp deletion mutation (NC_030814.1:rs656578433, g.79928824-79928832delAGTGTTCAC) was located upstream of the PRDM6 gene, and the 12 bp deletion variation (NC_030814.1:rs651603667, g: 79985625-79985636delTTGACTGATCCA) was located in intron 1 of PRDM6. Compared with the wild sequence, $9 \mathrm{bp}$ and $12 \mathrm{bp}$ sequences, respectively, were missing at these two sites. We designed two pairs of specific primers to amplify these two deletion mutations. The results show that only the 12 bp deletion locus was polymorphic in the 1044 SBWC goats. The 12 bp deletion within PRDM6 was detected by P2 (Table 1). The results of agarose gel electrophoresis and sequencing diagrams used to identify the genotypes of the $12 \mathrm{bp}$ variations within PRDM6 are presented in Figures 2 and 3 . The results show that the $12 \mathrm{bp}$ mutation locus of the PRDM6 gene was polymorphic and could be detected by agarose gel electrophoresis and Sanger sequencing. 


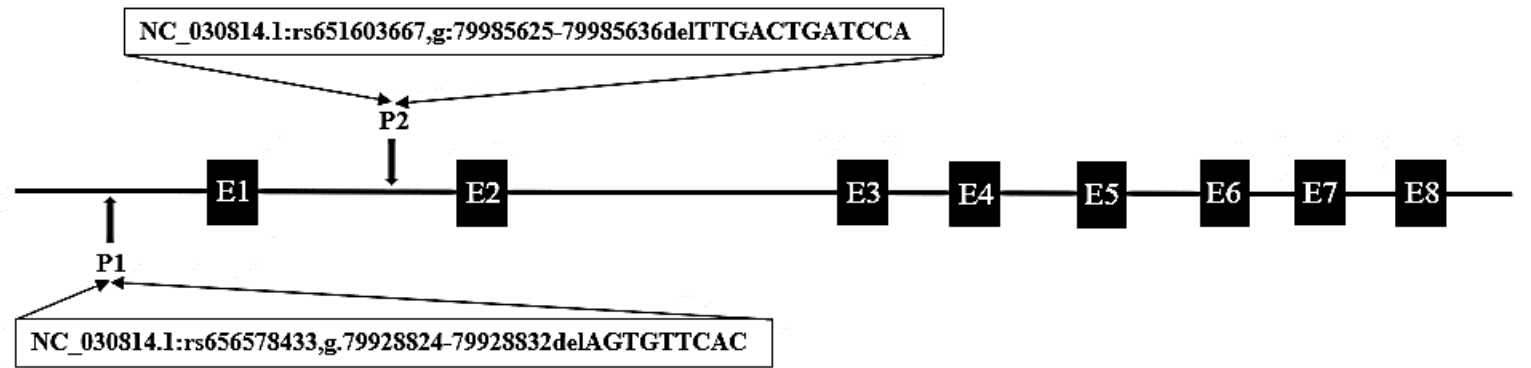

Figure 1. Mode pattern of goat PRDM6 gene variations position. The black arrows represent the mutation positions; the black boxes represent the number of exons of the goat PRDM6.

Table 1. Designed primers used for detecting deletion mutations of the goat PRDM6.

\begin{tabular}{clccc}
\hline Primers & \multicolumn{1}{c}{ Sequences $\left(\mathbf{5}^{\prime} \mathbf{- 3}^{\prime}\right)$} & Position & RS Number & Length (bp) \\
\hline \multirow{2}{*}{ PRDM6-P1 } & $\begin{array}{l}\text { F: GTTGATGAGGCAGGAGCCTT } \\
\text { R: GATGCCAGTTTTGTGCCTGG }\end{array}$ & upstream & rs656578433 & \multirow{2}{*}{126} \\
\hline \multirow{2}{*}{ PRDM6-P2 } & $\begin{array}{l}\text { F: GGATACAGGACAGTGTGGGC } \\
\text { R: CAACTCACTGAGCAAGGGGT }\end{array}$ & Intron 1 & rs651603667 & $287 / 275$ \\
\hline
\end{tabular}

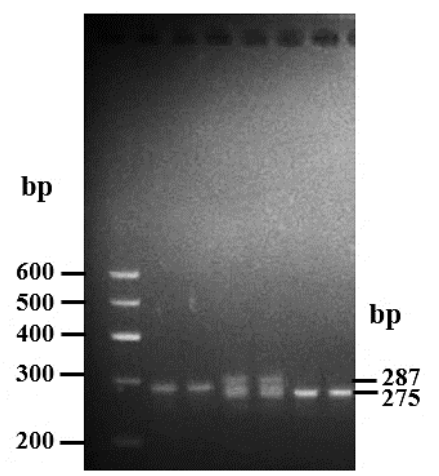

Figure 2. Electrophoresis pattern of the $12 \mathrm{bp}$ deletion locus within the goat PRDM6 gene. Results with marker, wt/wt, wt/wt, wt/del, wt/del, del/del, del/del display. Wildtype, wt/wt; heterozygote genotype, wt/del, homozygote deletion genotype, del/del.

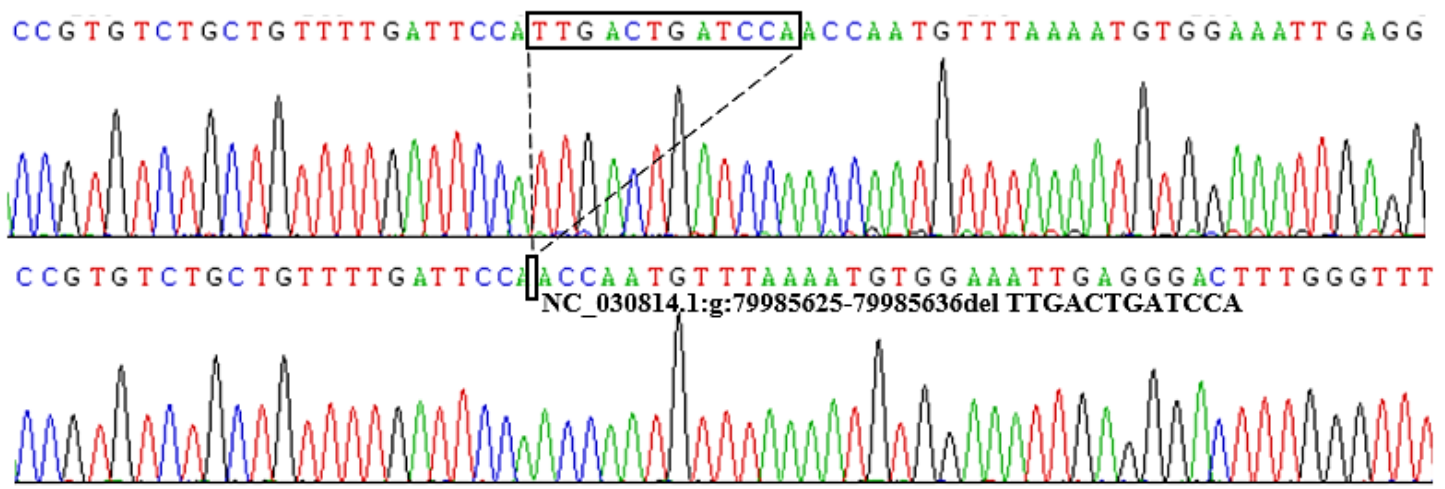

Figure 3. Sequencing diagram of the $12 \mathrm{bp}$ deletion locus within the goat PRDM6 gene. The sequence within the black border shows the difference in the sequence fragment.

\subsection{Genotyping and Genetic Parameters of Genetic Variations of the PRDM6 Gene}

The mean values and sample sizes of goat growth traits in yearling and adult goats are represented in Table 2. The results of electrophoresis show that the $12 \mathrm{bp}$ deletion variation within the PRDM 6 gene contained three genotypes, including homozygous wildtype (wt/wt genotype, $287 \mathrm{bp}$ ), heterozygote 
genotype (wt/del genotype, $287 \mathrm{bp}$ and $275 \mathrm{bp}$ ), and homozygous deletion genotype (del/del genotype, $275 \mathrm{bp}$ ) (Figure 2). According to the results of the three genotypes, sequence variation frequencies and population indexes of the $12 \mathrm{bp}$ mutation of PRDM6 in yearling and adult goats were calculated. In both populations, the genotype distributions in the $12 \mathrm{bp}$ variations within the PRDM6 gene were consistent with the HWE $(p>0.05)$ and were of medium genetic diversity $(0.25<$ PIC $<0.5)$ (Table 3$)$.

Table 2. Mean values of growth traits in yearling and adult Shaanbei white cashmere goats.

\begin{tabular}{ccccc}
\hline Traits & Yearling Population & Sizes & Adult Population & Sizes \\
\hline heart girth $(\mathrm{cm})$ & 73.12 & 529 & 83.48 & 421 \\
cannon circumference $(\mathrm{cm})$ & 7.45 & 530 & 8.21 & 421 \\
chest depth $(\mathrm{cm})$ & 25.89 & 530 & 29.46 & 421 \\
chest width $(\mathrm{cm})$ & 18.94 & 530 & 20.99 & 421 \\
body height $(\mathrm{cm})$ & 53.02 & 567 & 54.65 & 470 \\
body length $(\mathrm{cm})$ & 62.30 & 566 & 68.04 & 470 \\
Hip-width $(\mathrm{cm})$ & 13.03 & 530 & 14.99 & 421 \\
height at hip cross $(\mathrm{cm})$ & 55.28 & 530 & 57.66 & 418 \\
body weight $(\mathrm{kg})$ & 33.84 & 161 & 41.51 & 452 \\
\hline
\end{tabular}

Table 3. Sequence variation frequencies and population indexes for the mutation in Shaanbei white cashmere goats.

\begin{tabular}{|c|c|c|c|c|c|c|c|}
\hline \multirow{2}{*}{ Period } & \multirow{2}{*}{ Genotypes } & \multicolumn{2}{|c|}{ Frequency } & \multirow{2}{*}{ Ho } & \multirow{2}{*}{$\mathrm{He}$} & \multirow{2}{*}{ PIC } & \multirow{2}{*}{$\begin{array}{c}\chi^{2} \\
(p \text { Values })\end{array}$} \\
\hline & & Genotypes & Alleles & & & & \\
\hline $\begin{array}{c}\text { Yearling } \\
(18 \text { months old })\end{array}$ & $\begin{array}{l}\text { wt/wt }(n=321) \\
\text { wt/del }(n=211) \\
\text { del/del }(n=35)\end{array}$ & $\begin{array}{l}0.566 \\
0.372 \\
0.062\end{array}$ & $\begin{array}{c}0.752(\mathrm{I}) \\
0.248(\mathrm{D})\end{array}$ & 0.627 & 0.373 & 0.303 & $\begin{array}{c}0.002 \\
(p=0.967)\end{array}$ \\
\hline $\begin{array}{c}\text { Adult } \\
\text { (36 months old) }\end{array}$ & $\begin{array}{c}\text { wt/wt }(n=220) \\
\text { wt/del }(n=196) \\
\text { del/del }(n=61)\end{array}$ & $\begin{array}{l}0.461 \\
0.411 \\
0.128\end{array}$ & $\begin{array}{c}0.667(\mathrm{I}) \\
0.333(\mathrm{D})\end{array}$ & 0.556 & 0.444 & 0.346 & $\begin{array}{c}2.717 \\
(p=0.099)\end{array}$ \\
\hline Sum sample & $\begin{array}{c}\text { wt/wt }(n=541) \\
\text { wt/del }(n=407) \\
\text { del/del }(n=96)\end{array}$ & $\begin{array}{l}0.518 \\
0.390 \\
0.092\end{array}$ & $\begin{array}{c}0.713(\mathrm{I}) \\
0.287(\mathrm{D})\end{array}$ & 0.591 & 0.409 & 0.325 & $\begin{array}{c}2.326 \\
(p=0.127)\end{array}$ \\
\hline
\end{tabular}

\footnotetext{
Note: ' $n$ ' represents individual numbers. Ho, homozygosity; He, heterozygosity; PIC, polymorphism information content. Wildtype, $\mathrm{wt} / \mathrm{wt}$; heterozygote genotype, $\mathrm{wt} / \mathrm{del}$, homozygote deletion genotype, del/del.
}

\subsection{Correlations of the 12 bp Deletion within PRDM6 with Goat Growth Traits}

The genomic DNA of all 1044 goat individuals, including 567 yearlings (18 months old) and 477 adults (36 months old), was successfully extracted and genotyped. Associations between the $12 \mathrm{bp}$ deletion variation of $P R D M 6$ and growth traits of yearling SBWC goats were analyzed. For the yearling SBWC goats, analysis revealed that the 12 bp variation was associated with heart girth $(p=0.027)$, cannon circumference $(p=0.008)$, chest depth $\left(p=2.10 \times 10^{-5}\right)$, chest width $(p=0.004)$, body height $(p=0.032)$, body length $(p=0.044)$, and hip-width $(p=0.014)$. The influence of different genotypes on these traits was different $(p<0.05)$ (Table 4 and Figure 4$)$. For the adult SBWC goats, the analysis showed that the $12 \mathrm{bp}$ deletion was not associated with goat growth traits (Table 5 and Figure 5). 
Table 4. Effects of PRDM6 gene deletion mutations and growth traits of Shaanbei white cashmere goats in the yearling period (mean \pm standard errors).

\begin{tabular}{ccccc}
\hline Growth Traits & $\mathbf{w t} / \mathbf{w t}(\boldsymbol{n}=\mathbf{3 2 1})$ & $\mathbf{w t} / \mathbf{d e l}(\boldsymbol{n = 2 1 1})$ & del/del $(\boldsymbol{n = 3 5 )}$ & $\boldsymbol{p}$-Values \\
\hline HG $(\mathrm{cm})$ & $72.27^{\mathrm{c}} \pm 0.37(n=304)$ & $73.86^{\mathrm{b}} \pm 0.50(n=195)$ & $76.82^{\mathrm{a}} \pm 1.59(n=30)$ & 0.027 \\
$\mathrm{CC}(\mathrm{cm})$ & $7.37^{\mathrm{C}} \pm 0.04(n=305)$ & $7.54^{\mathrm{B}} \pm 0.05(n=195)$ & $7.65^{\mathrm{A}} \pm 0.15(n=30)$ & 0.008 \\
$\mathrm{CD}(\mathrm{cm})$ & $25.39^{\mathrm{C}} \pm 0.15(n=305)$ & $26.50^{\mathrm{B}} \pm 0.22(n=195)$ & $26.98^{\mathrm{A}} \pm 0.54(n=30)$ & $2.10 \times 10^{-5}$ \\
$\mathrm{CW}(\mathrm{cm})$ & $18.62^{\mathrm{C}} \pm 0.14(n=305)$ & $19.27^{\mathrm{B}} \pm 0.19(n=195)$ & $20.05^{\mathrm{A}} \pm 0.49(n=30)$ & 0.004 \\
BH $(\mathrm{cm})$ & $53.27^{\mathrm{a}} \pm 0.19(n=321)$ & $52.61^{\mathrm{b}} \pm 0.25(n=211)$ & $53.28^{\mathrm{ab}} \pm 0.48(n=35)$ & 0.032 \\
BL $(\mathrm{cm})$ & $61.93^{\mathrm{b}} \pm 0.24(n=321)$ & $62.71^{\mathrm{a}} \pm 0.29(n=210)$ & $63.31^{\mathrm{ab}} \pm 0.86(n=35)$ & 0.044 \\
HW (cm) & $12.81^{\mathrm{b}} \pm 0.09(n=305)$ & $13.29^{\mathrm{a}} \pm 0.15(n=195)$ & $13.63^{\mathrm{ab}} \pm 0.41(n=30)$ & 0.014 \\
HHC $(\mathrm{cm})$ & $55.40 \pm 0.20(n=305)$ & $55.02 \pm 0.26(n=195)$ & $55.86 \pm 0.54(n=30)$ & 0.223 \\
BWT $(\mathrm{kg})$ & $33.86 \pm 1.08(n=58)$ & $33.49 \pm 0.81(n=85)$ & $35.39 \pm 1.64(n=18)$ & 0.345 \\
\hline
\end{tabular}

Note: heart girth, HG; cannon circumference, CC; chest depth, CD; chest width, $\mathrm{CW}$; body height, $\mathrm{BH}$; body length, BL; hip-width, HW; height at the hip cross, HHC; body weight, BWT. Wildtype, wt/wt; heterozygote genotype, $\mathrm{wt} / \mathrm{del}$, homozygote deletion genotype, del/del. ' $n$ ' represents individual numbers. Cells with different letters $(\mathrm{A}, \mathrm{B}, \mathrm{C} ; \mathrm{a}, \mathrm{b}, \mathrm{c})$ differed significantly $(p<0.01 ; p<0.05)$.

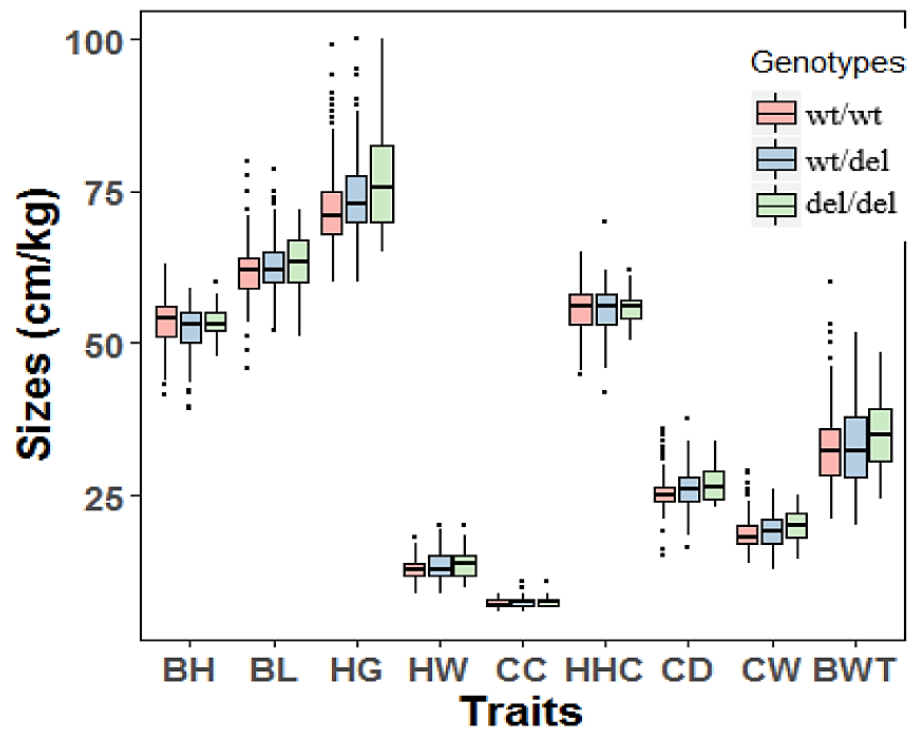

Figure 4. The associations between the $12 \mathrm{bp}$ deletion of PRDM6 and body measurement traits of yearling Shaanbei cashmere goats. Wildtype, wt/wt; heterozygote genotype, wt/del, homozygote deletion genotype, del/del. Body height $(\mathrm{cm}), \mathrm{BH}$; body length $(\mathrm{cm}), \mathrm{BL}$; heart girth $(\mathrm{cm}), \mathrm{HG}$; hip-width (cm), HW; cannon circumference (cm), CC; height at hip cross $(\mathrm{cm}), \mathrm{HHC}$; chest depth $(\mathrm{cm}), \mathrm{CD}$; chest width $(\mathrm{cm}), \mathrm{CW}$; body weight $(\mathrm{kg}), \mathrm{BWT}$.

Table 5. Effects of PRDM6 gene deletion mutations and growth traits of Shaanbei white cashmere goats in the adult period (mean \pm standard errors).

\begin{tabular}{ccccc}
\hline Growth Traits & $\mathbf{w t} / \mathbf{w t}(\boldsymbol{n = 2 2 0})$ & $\mathbf{w t} / \mathbf{d e l}(\boldsymbol{n}=\mathbf{1 9 6})$ & $\mathbf{d e l} / \mathbf{d e l}(\boldsymbol{n}=\mathbf{6 1})$ & $\boldsymbol{p}$-Values \\
\hline HG $(\mathrm{cm})$ & $83.16 \pm 0.64(n=192)$ & $83.28 \pm 0.64(n=173)$ & $85.21 \pm 1.25(n=56)$ & 0.121 \\
CC $(\mathrm{cm})$ & $8.18 \pm 0.05(n=191)$ & $8.24 \pm 0.06(n=173)$ & $8.21 \pm 0.10(n=57)$ & 0.421 \\
CD $(\mathrm{cm})$ & $29.51 \pm 0.25(n=193)$ & $29.50 \pm 0.25(n=172)$ & $29.19 \pm 0.44(n=56)$ & 0.531 \\
CW $(\mathrm{cm})$ & $21.05 \pm 0.28(n=193)$ & $20.84 \pm 0.29(n=172)$ & $21.27 \pm 0.53(n=56)$ & 0.472 \\
BH $(\mathrm{cm})$ & $54.24 \pm 0.29(n=217)$ & $54.95 \pm 0.33(n=193)$ & $55.19 \pm 0.49(n=60)$ & 0.102 \\
BL $(\mathrm{cm})$ & $68.05 \pm 0.37(n=217)$ & $67.87 \pm 0.43(n=193)$ & $68.55 \pm 0.74(n=60)$ & 0.423 \\
HW $(\mathrm{cm})$ & $14.87 \pm 0.13(n=191)$ & $14.99 \pm 0.16(n=173)$ & $15.39 \pm 0.31(n=57)$ & 0.085 \\
HHC $(\mathrm{cm})$ & $57.41 \pm 0.30(n=192)$ & $57.68 \pm 0.40(n=171)$ & $58.45 \pm 0.50(n=55)$ & 0.280 \\
BWT $(\mathrm{kg})$ & $40.85 \pm 0.74(n=205)$ & $41.63 \pm 0.80(n=186)$ & $43.39 \pm 1.59(n=61)$ & 0.112 \\
\hline
\end{tabular}

Note: heart girth, HG; cannon circumference, CC; chest depth, CD; chest width, CW; body height, BH; body length, BL; hip-width, HW; height at hip cross, HHC; body weight, BWT. ' $n$ ' represents individual numbers. Wildtype, $\mathrm{wt} / \mathrm{wt}$; heterozygote genotype, wt/del, homozygote deletion genotype, del/del. 


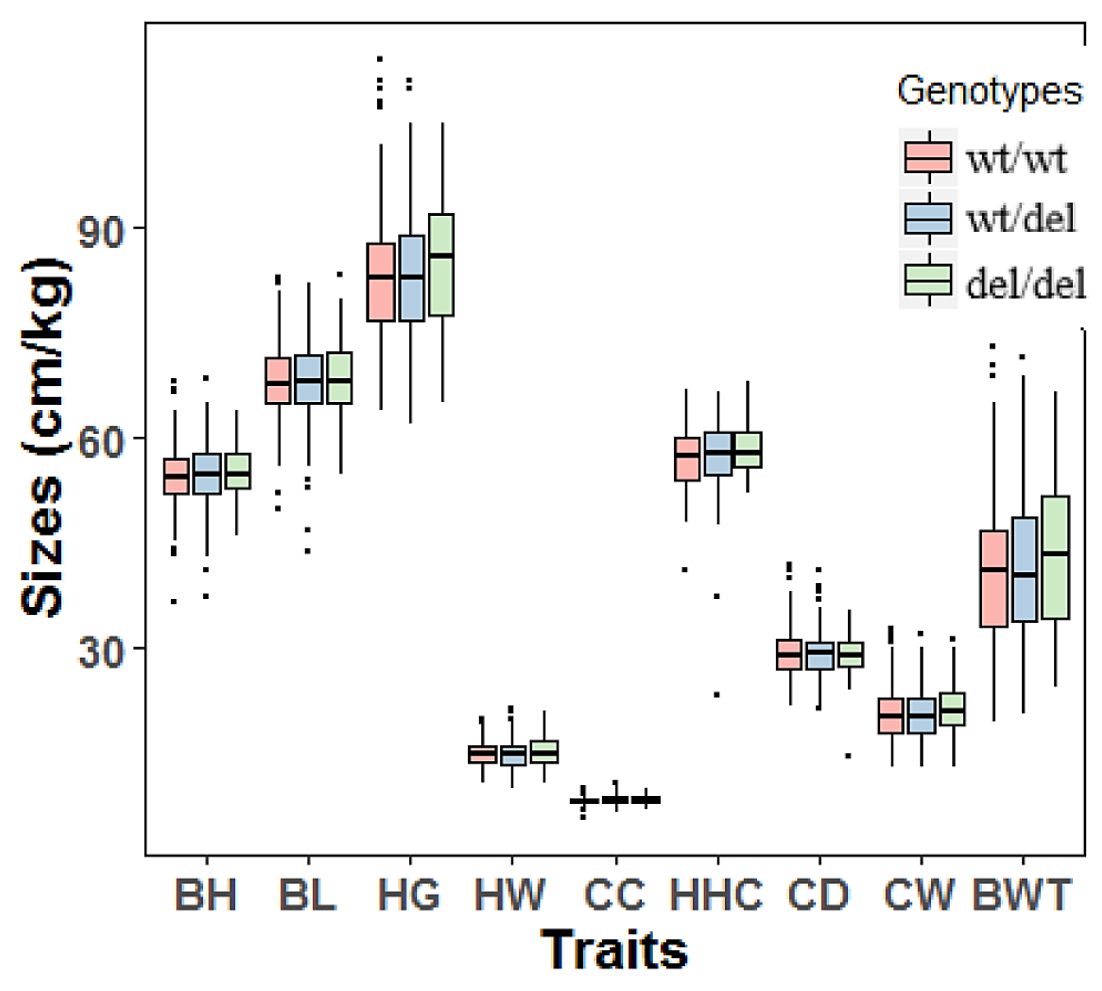

Figure 5. The associations of the $12 \mathrm{bp}$ variation of PRDM6 and body measurement traits of adult Shaanbei cashmere goats. Wildtype, wt/wt; heterozygote genotype, wt/del, homozygote deletion genotype, del/del. Body height $(\mathrm{cm}), \mathrm{BH}$; body length $(\mathrm{cm}), \mathrm{BL}$; heart girth $(\mathrm{cm}), \mathrm{HG}$; hip-width $(\mathrm{cm})$, HW; cannon circumference (cm), CC; height at hip cross $(\mathrm{cm}), \mathrm{HHC}$; chest depth $(\mathrm{cm}), \mathrm{CD}$; chest width (cm), CW; body weight (kg), BWT.

\section{Discussion}

Recently, by GWAS studies, the PRDM6 gene was shown to affect multiple, apparently unrelated inherited traits, including bone density and body mass index; therefore, it was considered as a potentially pleiotropic gene [12,13]. In this study, we wanted to investigate whether PRDM6 mutations were correlated with body shape and growth-related traits, and we first verified one 12 bp deletion variant located in intron 1 of the goat PRDM6 gene. For heart girth, cannon circumference, chest depth, and chest width traits of yearling goats, del/del carriers were better than wildtypes, and there were differences between different genotypes and growth traits in yearling goats (Tables 4 and 5, and Figures 4 and 5). The formation of the skeleton is part of the early development of an organism. Therefore, it is our belief that the PRDM6 gene affects goat growth in the yearling period, and body sizes might be affected by early skeletal development. This study is consistent with the results of previous studies and demonstrates the validity of our hypothesis. For body height, body length, and hip-width traits, there were no differences between $\mathrm{wt} / \mathrm{wt}$ genotypes and del/del genotypes. This might be due to the involvement of other genes to regulate these traits. Because multiple genes control goat growth traits, there may be various genes co-regulated in the growth and development of adult goats. Taken together, the 12 bp deletion variation of the PRDM6 gene plays a vital role in the early growth and development of goats. By the $12 \mathrm{bp}$ mutation, breeders can quickly and effectively select excellent individual goats at an early stage.

PRDM6 belongs to the PRDM family, which possesses C-terminal Krüppel-type zinc finger motifs and the N-terminal PR domain. The PR domain could interact with some essential proteins, such as histone methyltransferase [26,27]. There have been reports showing that PRDM6, as a methyltransferase, was considered to be involved in the histone methylation mechanism in development and reproduction $[28,29]$. Histone methylation could regulate organic growth and development by 
epigenetic modification [30,31]. Many studies have proven specific associations between histone methylation and growth and obesity [32-34]; therefore, the PRDM6 gene might affect goat growth and development by being associated with histone methylation. Meanwhile, PRDM6 is abundant in vascular precursors and inhibits the proliferation and survival program of endothelial cells, so it is critical in maintaining gene expression and cell homeostasis [28,35]. Recently, some reports found that the PRDM6 gene acted as a potentially pleiotropic gene associated with osteoporosis and obesity [12,13], which illustrates that it may participate in regulating growth and development in various ways.

Prior studies found that introns had a positive effect on gene expression in various ways; for example, a nucleotide mutation in intron 3 of porcine IGF2 could affect skeletal muscle by specifically binding to the transcription factor ZBED6 protein [8,36]. Similarly, we wanted to investigate whether this mutation site could affect transcription factor binding differently. According to the AliBaba 2.1 website (http://gene-regulation.com/pub/programs/alibaba2/), compared with the deletion sequence, the $12 \mathrm{bp}$ wild sequence could differently bind to the estrogen receptor (ER) transcription factor (Figure 6). The ER transcription factor has been reported to be essential for bone metabolism via a variety of mechanisms in osteoblasts, osteocytes, and osteoclasts to maintain bone mineral density [37,38]. Thus, we hypothesized that the $12 \mathrm{bp}$ deletion variation might affect the growth process by this transcription factor to regulate PRDM6 gene expression, but the specific reasons still need further study. Meanwhile, Mandon-Pépin et al. reported that the GDF9 gene was differentially expressed at the different growth stages of sheep [39]; therefore, we speculated that differences might be due to the differential expression of the PRDM6 gene in yearling and adult stages.

Wildtype sequence

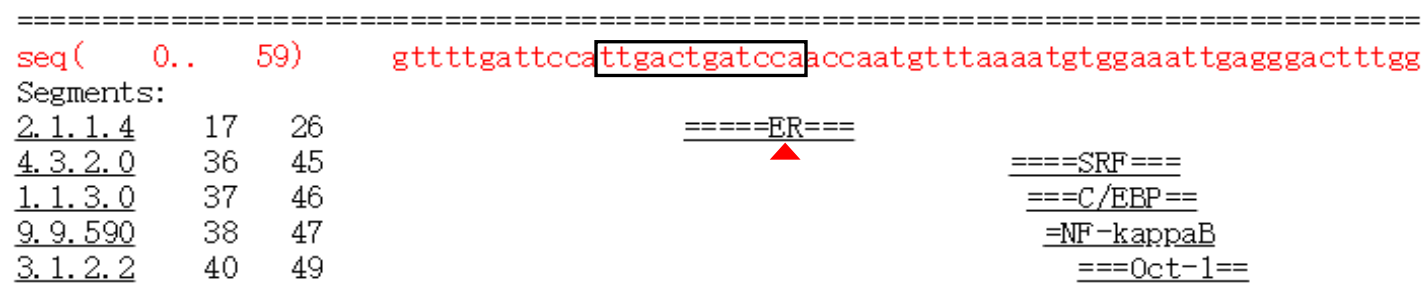

Deletion sequence

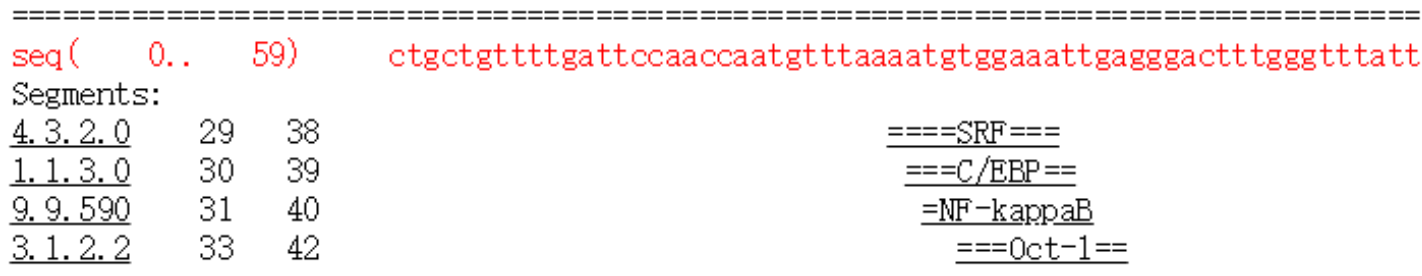

Figure 6. Bioinformatics predicted transcription factor binding sites on the $12 \mathrm{bp}$ mutation sequences of the PRDM6 gene. The black box highlights the potential transcriptional factor, estrogen receptor (ER), differentially appearing in wildtype sequences. The red triangle represents the differential binding of transcription factors.

For the 12 bp deletion mutation, del/del carriers represented better growth-related traits in yearling goats, including heart girth, cannon circumference, chest depth, and chest width traits. There were differences between different genotypes and growth traits in yearling goats, which illustrates that this mutation might exert a large influence in the early growth and development of goats. As we know, the economic value of goats depends on good growth traits as well as the speed of growth. In the process of raising goats, it is of considerable significance to select individuals with a fast growth rate and large body size to improve the economic benefit of the goat industry. In this study, del/del carriers had better 
body weight and growth traits than wt/wt and wt/del genotype individuals in yearling goats. With the development of modern breeding technology in the future, by selecting this genetic site, breeders can quickly and efficiently carry out early selective breeding of young individuals with better body shape and growth traits. In this way, goats can reach body maturity faster and improve the economic benefit of goat farms, so the $12 \mathrm{bp}$ deletion variation could provide some scientific basis for the efficient and rapid development of the goat industry, and be regarded as an effective molecular marker for goat breeding selection in the early growth stage.

\section{Conclusions}

A 12 bp deletion mutation within PRDM6 was identified, and we found that this mutation could affect multiple growth traits of SBWC goats. For heart girth, cannon circumference, chest depth, and chest width traits, compared with wt/wt and wt/del carries, del/del genotypes had the best growth traits in yearling goats. Totally, this $12 \mathrm{bp}$ deletion variation plays a vital role in the early growth and development of goats. It could be used as a useful molecular marker for the early selection of superior individuals in goat breeding.

Author Contributions: Resources, Z.W., C.W., Y.G., S.S., B.W., Y.J., Y.B., L.S., L.Q.; Conducting experiment, C.W., Y.G., S.S., Z.W. Project administration, X.L., X.S., L.L.; Data curation, C.W., H.Z.; Writing-original draft, Z.W.; Writing-review \& editing, X.L. and H.Z. All authors have read and agreed to the published version of the manuscript.

Funding: This research was funded by the National Natural Science Foundation of China (31702115).

Acknowledgments: Thanks for the organizations of Life Science Research Center, Yulin University (Shaanxi, China), and Shaanxi Provincial Engineering and Technology Research Center of Cashmere Goats (Shaanxi, China), for samples, data collection. Thanks for the organizations of the College of Animal Science and Technology, Northwest A\&F University (Yangling, Shaanxi, China) and Life Science Research Core Services, Northwest A\&F University (Yangling, Shaanxi, China) for experiment supporting.

Conflicts of Interest: The authors declare no conflict of interest.

\section{References}

1. Van Heerden, S.M.; Strydom, P.E. Nutrient retention values and cooking yield factors for three South African lamb and mutton cuts. J. Sci. Food Agric. 2017, 97, 5037-5042. [CrossRef]

2. Flakemore, A.R.; Malau-Aduli, B.S.; Nichols, P.D.; Malau-Aduli, A. Omega-3 fatty acids, nutrient retention values, and sensory meat eating quality in cooked and raw Australian lamb. Meat Sci. 2017, 123, $79-87$. [CrossRef] [PubMed]

3. Coelho, T.; Braga, F.; Silva, N.; Dantas, C.; Lopes, J.C.; de Sousa, S.; Vieira, E.C. Optimization of the protein extraction method of goat meat using factorial design and response surface methodology. Food Chem 2019, 281, 63-70. [CrossRef] [PubMed]

4. Zhao, W.; Zhong, T.; Wang, L.J.; Li, L.; Zhang, H.P. Extensive female-mediated gene flow and low phylogeography among seventeen goat breeds in southwest China. Biochem. Genet. 2014, 52, 355-364. [CrossRef] [PubMed]

5. Wang, X.; Yang, Q.; Wang, K.; Zhang, S.; Pan, C.; Chen, H.; Qu, L.; Yan, H.; Lan, X. A novel 12-bp indel polymorphism within the GDF9 gene is significantly associated with litter size and growth traits in goats. Anim. Genet. 2017, 48, 735-736. [CrossRef]

6. La, Y.F.; Liu, Q.Y.; Zhang, L.P.; Chu, M.X. Single nucleotide polymorphisms in SLC5A1, CCNA1, and ABCC1 and the association with litter size in Small-tail han sheep. Animals 2019, 9, 432. [CrossRef]

7. Li, W.; Liu, D.; Tang, S.; Li, D.; Han, R.; Tian, Y.; Li, H.; Li, G.; Li, W.; Liu, X.; et al. A multiallelic indel in the promoter region of the Cyclin-dependent kinase inhibitor 3 gene is significantly associated with body weight and carcass traits in chickens. Poult. Sci. 2019, 98, 556-565. [CrossRef]

8. Van Laere, A.S.; Nguyen, M.; Braunschweig, M.; Nezer, C.; Collette, C.; Moreau, L.; Archibald, A.L.; Haley, C.S.; Buys, N.; Tally, M.; et al. A regulatory mutation in IGF2 causes a major QTL effect on muscle growth in the pig. Nature 2003, 425, 832-836. [CrossRef] 
9. Knorst, V.; Byrne, S.; Yates, S.; Asp, T.; Widmer, F.; Studer, B.; Kolliker, R. Pooled DNA sequencing to identify SNPs associated with a major QTL for bacterial wilt resistance in Italian ryegrass (Lolium multiflorum Lam.). Theor. Appl. Genet. 2019, 132, 947-958. [CrossRef]

10. Wang, X.; Yang, Q.; Wang, K.; Yan, H.; Pan, C.; Chen, H.; Liu, J.; Zhu, H.; Qu, L.; Lan, X. Two strongly linked single nucleotide polymorphisms (Q320P and V397I) in GDF9 gene are associated with litter size in cashmere goats. Theriogenology 2019, 125, 115-121. [CrossRef]

11. Wang, Z.; Zhang, X.; Jiang, E.; Yan, H.; Zhu, H.; Chen, H.; Liu, J.; Qu, L.; Pan, C.; Lan, X. InDels within Caprine IGF2BP1 intron 2 and the $3^{\prime}$-untranslated regions are associated with goat growth traits. Anim. Genet. 2019, 51, 117-121. [CrossRef] [PubMed]

12. Hu, Y.; Tan, L.J.; Chen, X.D.; Liu, Z.; Min, S.S.; Zeng, Q.; Shen, H.; Deng, H.W. Identification of novel potentially pleiotropic variants associated with osteoporosis and obesity using the cFDR method. J. Clin. Endocrinol. Metab. 2017, 103, 125-138. [CrossRef] [PubMed]

13. Riveros-McKay, F.; Mistry, V.; Bounds, R.; Hendricks, A.; Keogh, J.M.; Thomas, H.; Henning, E.; Corbin, L.J.; Understanding Society Scientific Group; O’Rahilly, S.; et al. Genetic architecture of human thinness compared to severe obesity. PLoS Genet. 2019, 15, e1007603. [CrossRef] [PubMed]

14. Jung, K.Y.; Kim, K.M.; Ku, E.J.; Kim, Y.J.; Lee, D.H.; Choi, S.H.; Jang, H.C.; Shin, C.S.; Park, K.S.; Lim, S. Age-and sex-specific association of circulating osteocalcin with dynamic measures of glucose homeostasis. Osteoporos. Int. 2016, 27, 1021-1029. [CrossRef]

15. Boskey, A.L.; Imbert, L. Bone quality changes associated with aging and disease: A review. Ann. N. Y. Acad. Sci. 2017, 1410, 93-106. [CrossRef]

16. Yang, Q.; Yan, H.; Li, J.; Xu, H.; Wang, K.; Zhu, H.; Chen, H.; Qu, L.; Lan, X. A novel 14-bp duplicated deletion within goat GHR gene is significantly associated with growth traits and litter size. Anim. Genet. 2017, 48, 499. [CrossRef]

17. Zhang, S.; Jiang, E.; Wang, K.; Zhang, Y.; Yan, H.; Qu, L.; Chen, H.; Lan, X.; Pan, C. Two Insertion/Deletion Variants within SPAG17 Gene Are Associated with Goat Body Measurement Traits. Animals 2019, 9, 379. [CrossRef]

18. Aljanabi, S.M.; Martinez, I. Universal and rapid salt-extraction of high quality genomic DNA for PCR-based techniques. Nucleic Acids Res. 1997, 25, 4692-4693. [CrossRef]

19. Chen, M.; Wang, J.; Liu, N.; Cui, W.; Dong, W.; Xing, B.; Pan, C. SOX9: Expression profiles of sertoli cell (SCs) and a functional $18 \mathrm{bp}$ indel affecting testis weight. Theriogenology 2019, 138, 94-101. [CrossRef]

20. Zhu, H.; Zhang, Y.; Bai, Y.; Yang, H.; Yan, H.; Liu, J.; Shi, L.; Song, X.; Li, L.; Dong, S.; et al. Relationship between SNPs of POU1F1 gene and litter size and growth traits in Shaanbei white cashmere goats. Animals 2019, 9, 114. [CrossRef]

21. Chen, M.; Yan, H.; Wang, K.; Cui, Y.; Chen, R.; Liu, W.; Zhu, H.; Qu, L.; Pan, C. Goat SPEF2: Expression profile, indel variants identification and association analysis with litter size. Theriogenology 2019, 139, 147-155. [CrossRef] [PubMed]

22. Zhao, H.; Wu, X.; Cai, H.; Pan, C.; Lei, C.; Chen, H.; Lan, X. Genetic variants and effects on milk traits of the caprine paired-like homeodomain transcription factor 2 (PITX2) gene in dairy goats. Gene 2013, 532, $203-210$. [CrossRef] [PubMed]

23. Wu, X.; Jia, W.; Zhang, J.; Li, X.; Pan, C.; Lei, C.; Chen, H.; Dang, R.; Lan, X. Determination of the novel genetic variants of goat STAT5A gene and their effects on body measurement traits in two Chinese native breeds. Small Ruminant Res. 2014, 121, 232-243. [CrossRef]

24. Chen, F.; Shi, J.; Luo, Y.Q.; Sun, S.Y.; Pu, M. Genetic characterization of the gypsy moth from China (Lepidoptera, Lymantriidae) using inter simple sequence repeats markers. PLoS ONE 2013, 8, e73017. [CrossRef] [PubMed]

25. Kang, Z.; Zhang, S.; He, L.; Zhu, H.; Wang, Z.; Yan, H.; Huang, Y.; Dang, R.; Lei, C.; Chen, H.; et al. A 14-bp functional deletion within the CMTM2 gene is significantly associated with litter size in goat. Theriogenology 2019, 139, 49-57. [CrossRef] [PubMed]

26. Gewies, A.; Castineiras-Vilarino, M.; Ferch, U.; Jährling, N.; Heinrich, K.; Hoeckendorf, U.; Przemeck, G.K.; Munding, M.; Groß, O.; Schroeder, T.; et al. Prdm6 is essential for cardiovascular development in vivo. PLoS ONE 2013, 8, e81833. [CrossRef] [PubMed] 
27. Li, N.; Subrahmanyan, L.; Smith, E.; Yu, X.; Zaidi, S.; Choi, M.; Mane, S.; Nelson-Williams, C.; Behjati, M.; Kazemi, M.; et al. Mutations in the histone modifier PRDM6 are associated with isolated nonsyndromic patent ductus arteriosus. Am. J. Hum. Genet. 2016, 98, 1082-1091. [CrossRef] [PubMed]

28. Wu, Y.; Ferguson, J.E.; Wang, H.; Kelley, R.; Ren, R.; McDonough, H.; Meeker, J.; Charles, P.C.; Wang, H.; Patterson, C. PRDM6 is enriched in vascular precursors during development and inhibits endothelial cell proliferation, survival, and differentiation. J. Mol. Cell Cardiol. 2008, 44, 47-58. [CrossRef]

29. Fellous, A.; Earley, R.L.; Silvestre, F. The Kdm/Kmt gene families in the self-fertilizing mangrove rivulus fish, Kryptolebias marmoratus, suggest involvement of histone methylation machinery in development and reproduction. Gene 2019, 687, 173-187. [CrossRef]

30. Kitsiou-Tzeli, S.; Tzetis, M. Maternal epigenetics and fetal and neonatal growth. Curr. Opin. Endocrinol. Diabetes Obes. 2017, 24, 43-46. [CrossRef]

31. Gan, Y.M.; Zhou, J.; Quan, R.; Hong, L.J.; Li, Z.C.; Zheng, E.Q.; Liu, W.; Wu, Z.F.; Cai, G.Y.; Gu, T. Histone H3K27me3 in the regulation of skeletal muscle development. Hereditas 2019, 41, 285-292. [CrossRef] [PubMed]

32. Martínez, J.A.; Milagro, F.I.; Claycombe, K.J.; Schalinske, K.L. Epigenetics in adipose tissue, obesity, weight loss, and diabetes. Adv. Nutr. 2014, 5, 71-81. [CrossRef] [PubMed]

33. Marco, A.; Kisliouk, T.; Tabachnik, T.; Weller, A.; Meiri, N. DNA CpG methylation (5-methylcytosine) and its derivative (5-hydroxymethylcytosine) alter histone posttranslational modifications at the Pomc promoter, affecting the impact of perinatal diet on leanness and obesity of the offspring. Diabetes 2016, 65, 2258-2267. [CrossRef] [PubMed]

34. Pigeyre, M.; Yazdi, F.T.; Kaur, Y.; Meyre, D. Recent progress in genetics, epigenetics and metagenomics unveils the pathophysiology of human obesity. Clin. Sci. 2016, 130, 943-986. [CrossRef] [PubMed]

35. Chi, J.; Cohen, P. The multifaceted roles of PRDM16: Adipose biology and beyond. Trends Endocrinol. Metab. 2016, 27, 11-23. [CrossRef]

36. Xiang, G.; Ren, J.; Hai, T.; Fu, R.; Yu, D.; Wang, J.; Li, W.; Wang, H.; Zhou, Q. Editing porcine IGF2 regulatory element improved meat production in Chinese Bama pigs. Cell Mol. Life Sci. 2018, 75, 4619-4628. [CrossRef]

37. Khalid, A.B.; Krum, S.A. Estrogen receptors alpha and beta in bone. Bone 2016, 87, 130-135. [CrossRef]

38. Iravani, M.; Lagerquist, M.; Ohlsson, C.; Sävendahl, L. Regulation of bone growth via ligand-specific activation of estrogen receptor alpha. J. Endocrinol. 2017, 232, 403-410. [CrossRef]

39. Mandon-Pépin, B.; Oustry-Vaiman, A.; Vigier, B.; Piumi, F.; Cribiu, E.; Cotinot, C. Expression profiles and chromosomal localization of genes controlling meiosis and follicular development in the sheep ovary. Biol. Reprod. 2003, 68, 985-995. [CrossRef] 